\title{
Modelling the Causal Relationship between Extremism of Response, Psychopathy and Intellectual Deviation among Secondary School Students
}

\author{
Dr. Hani Sulaiman Al-Khalidi \\ Department of Classroom teacher \\ Faculty of Arts - Isra University
}

\begin{abstract}
This research aims to test the validity of the theoretical relationship between the variables of extremism of response, psychopathy and intellectual deviation as illustrated by the proposed model. In light of what the collected data indicate, this study attempts to propose a model that specifies the effects of a number of variables on intellectual deviation. Furthermore, the study aims to identify whether there is an indirect effect of extremism of response on intellectual deviation. The sample of the study consisted of (514) high school students in Riyadh, Saudi Arabia. The researcher employed scales of extremism of response, psychopathy and intellectual deviation. The researcher adopted the track analysis method to identify the interaction between the variables employed in this research through a causal model. The most significant results were a direct effect of extremism of response on intellectual deviation, whilepsychopathy was not suggested as a moderating variable between extremism of response and intellectual deviation. The best model among the two proposed models was the one that was omitted from the three scales of weak items.
\end{abstract}

Keywords: psychopathology, extremism of response, intellectual deviation, modelling, track analysis

\section{Introduction:}

Modelling of structural equation has become a key focus of many research studies. It has been increasingly adopted indifferent sciences (e.g., educational, psychological, social, behavioural). Although it appeared in the early 1970s by Joresko (1970), it has become more pervasive and has been selected by many researchers since the late of twentieth century. Some of the main reasons for dissemination of modelling of structural equation include: the existence of specialized computer programs, the availability of specialized references and previous studies, the emergence of specialized journals dealing with applications and methodological issues associated with them, and the existence of courses dealing with this statistical methodology taught at the postgraduate level. The world has witnessed numerous and devastating incidents that have resulted in the destruction of human and economic resources and infrastructure. These incidents were linked to criminal schemes aimed at disrupting security and destabilizing society. Moreover, they were clearly associated with intellectual deviation and extremism which resulted in many destructive and extremist ideas and beliefs which aimed at breaking the laws of the countries and ending up with violence and destruction against everything at societies (Al-Khalidi, 2007).

It has been shown that the phenomenon of intellectual deviation is regarded to many interrelated and complex factors. Furthermore, its association with a complex psychological phenomenon called psychopathy is what makes intellectual deviation a very complicated phenomenon. The psychopathic character is a pathological person who is characterized as having moral deviation, practicing violence and committing crimes. Therefore, such character can be considered as anti-society whois willing to commit a lot of wrongdoings (Aresneault etal., 2000).

The psychopathic personality is a characteristic that calls on those whose actions and behaviours deviate from proper social norms, laws, regulations and ethical standards. Psychopathic individuals are harmful to other community members and harmful to the whole society and its various institutions as well. They usually feel pleasure when they see others in distress or dilemma. Moreover, they do not correspond with other personalities and are not able to adapt or integrate with the surrounding environment. They do not respond to advice or guidanceor even punishment and do not learn from the lessons or experiences that they are exposed to. Psychopathic persons are also known as having dull emotions, being careless and reckless and not able to take responsibility (Barakat, 1995).

Psychopaths are further known as doing compulsive actions because they are controlled by an idea or a set of ideas. They may also find themselves under the control of a repetitive, urgent and coercive behavioural patterns. The psychopathic person has no way of resisting them and remains nervous until he does the intended behaviour. When a person insists on a desire or motivation, and that person is unable to meet this urgency, the only solution that he sees fit is to use the power of the ego to get rid of what he urges in order to stay distance from oppression. 
Thus, he does not get rid of the urgency of the presumed desire but postpones it to another occasion. Such occasion become ultimate when the ego weakens and loses its coordinating role within the character for some reason. The repressed person hence appears with all his power and cruelty to achieve that desire regardless of the rules and laws at his society (Saad and Na'amah, 1993).

Therefore, the behaviour of psychopathic personality is characterized by several aspects, including quarrels, gang formation and the destruction of public property. The ones with psychopathic personality turn to the criminal path that helps them deviate intellectually to become one of the most dangerous and serious phenomena that can damage and destroy society. The seriousness of this phenomenon is seen in the extreme views which the psychopath adopts which can be translated in different forms of intellectual deviation. The psychopath always believes that he is absolutely right in his thought and belief. He further condemns or even antagonizes anyone who disagrees with his beliefs. He is also willing to use violence against anyone who disagrees with him. These dangerous ideas are closely related to extremism of responses because the characteristics of psychopathic personality are related to the characteristics of extremist responses.

The psychopathic characters are characterized with radicalism in the provisions, stubbornness and the adoption of many beliefs about self and life without logical evidence based on science. These radicalized beliefs include authoritarian and dogmatic inertia and intellectual deviation. Therefore, they do not use logic in their actions but use emotions, force and violence which prevent them to act in full freedom or will (Ibrahim, 1994). Therefore, the psychopathic personality and the person with extreme responses share almost identical characteristics such as sclerosis and violence. They are often emotional people who tend to be stressed and break the law. This makes them more prepared for intellectual deviation. For this reason, this study adopted the suitable causal model to investigate these interrelated variables.

\section{The Problem of the Study}

There are many phenomena, evidence and facts that are highly relevant to psychopathic character. The United Nations (UN) reports have confirmed that the phenomenon of violence worldwide has increased in varying proportions such as physical violence and sexual abuse (Moon, 2007; Nowaak, 2008). The results of several Arab studies, such as the Majdoub study (2003) and Assi (2006), indicated that young people imitate each other in many misconducts that are far from tradition and values such as vigilance, drug addiction, alcohol consumption and violence, all of which are characteristic of psychopathic personality. Therefore, a psychopathic character has a tendency towards extremism, which in turn leads to terrorism that has engulfed the Arab world in the past decades. People characterised as psychopathic are intolerance, close minded, lack acceptance of the other and adopting radical ideas that are far from the norms and customs prevailing in society which makes such persons a threat to their society. Thus, those people are close-minded and fully confident that they have the right belief. They do not accept any other beliefs that are different from theirs which is a feature that distinguishes those with extreme responses. Such feature is identical with the psychopathic personality on the one hand and linked to the characteristics of the intellectually deviantson the other hand (Brengelmann, 1960). It turned out that most adherents of deviant thoughts are young people and adolescence, according to what was published about this phenomenon in various mediaas well as some studies that explored intellectual deviation (e.g., Al-Juhani, 2004). Consequently, the researcher has chosen the sample from secondary school students to conduct this study.

Viewinga number of studies that investigated intellectual deviation, extremism of response and psychopathy, it can be noted that most of these studies focused on examining whether there is a significant relationship between these variables or not. However, the researcher suggests that this relationship should be analysed and explained, instead of exploring whether this relationship exists or not. It is assumed that there are many causes and variables that contribute significantly to the interpretation of these relationships. Therefore, the causal models are considered the best models for studying these relationships. It is predicted that causal relationships provide more accurate and deeper understanding of how these variables are linked to each other. Causal modelling depends primarily on the analysis of the relationships between variables in the models based on scientific theories or based on reasonable grounds. The existence of a relationship between two variables does not mean that the independent variable is the cause of the dependent variable or vice versa (Sharabajee, 1981). But the causal model enables us to understand the relationships between variables. Hence, departing from this perspective, the problem of this research emerged to identify a causal model that links important variables that are directly related to the intellectual deviation of young people, especially high school students. To tackle this research problem, the following key research question is formed: What is the systemic causal model that explains the relationship between extremism of response, psychopathy and intellectual deviation among secondary school students?

\section{Objectives of the study:}


The aim of this research is to test the statistical model which is proposed based on the hypothetical relationship between the three variables (extremism of response, psychopathy and intellectual deviation). Thus, access to a statistical model illustrates the importance of the variables and their impact on intellectual deviation in light of data matching the proposed model. Therefore, the main objective of the research is to examine the role of psychopathy as a mediating variable of the relationship between extremism of response and intellectual deviation.

\section{The importance of the study:}

The research is mainly concerned with the intellectual deviation of secondary school students, and deals with the impact of the variables, i.e. extremism of response and psychopathy on intellectual deviation based on the results of a number of studies in this regard. The importance of the study is that it deals with a very important statistical method, i.e. modelling (or path analysis). This study is tackling this research gap in more detail,as this important statistical method is rarely adopted in the Arab context. Having reached an ideal causal model linking the three variables will provide more information to educators and psychologists to help them diminish the characteristics of psychopathic personality and extremism of response, which reduces the deviation of thought and misguided ideas among high school students.

\section{Study concepts and terminology:}

\section{The concept of intellectual deviation}

Intellect in language: Intellect is defined as: "the realization of the sake of the thing" (Ibn Manzaru, 1999, p. 307).

Intellectas an idiom: It is defined as: "the product of thinking, if accumulated through individuals and over time, it becomes a cumulative group that represents the sum of mental visions on a particular subject" (Shahrani, 2005, p. 8).

Deviation as an idiom: It is defined as: "The contradictory behaviourof accepted norms and values that constitute harassment, social danger or threat to the future" (Rifai, 1991, p. 13).

Intellectual Deviation as an idiom: It is known as: "departure from the seriousness of righteousness, distance from the moderate centre, leaving the balance, and adhere to the side of and issue without any proved fact" (Zuhaili, 1993, p. 163).

Procedural definition of Intellectual Deviation: It is the degree to which the respondent gets on the intellectual deviation scale used in his study (Otaibi, 2016).

Psychopathy as an idiom: Psychopathy is defined as: "the attributes or qualities that we call upon every individual whose actions or behaviour indicate departing from the moral principles and standards of society" (Mansour, 2014).

Procedural definition of Psychopathy: The degree to which the respondent gets on the psychopathy scale used in this study.

Extremism ofresponse as an idiom: It is defined as: "A rigid response that lacks adaptability and scalability to meet the spontaneity of others."

Procedural definition of extremism of response: The degree to which the respondent obtains on the scale of extremism of response used in this study.

The limitation of the study: The study was limited to a sample of high school students in Al-Riyadh in the first semester of the academic year 2017/2018. It included the top three grades in a high school where data were collected.

Previous studies: The researcher will review the previous studies according to the variables of the current study. This review will be limited to present the findings of these studies as follow: First: Studies dealing with one of the three variables of the study Second: Studies linked two variables of the study

\section{First: Studies dealing with one of the three variables of the study}

\section{(A) Studies on extremism of response}

Berg and Collir (1953) conducted a study to test the hypothesis which says that the tendency to choose extreme responses on a sentimental response scale when answering a series of mysterious test items are stable and reflect certain differences in personality and group. The study sample consisted of (634) black and white students from North-western University. The researchers used the descriptive analytical method in this study. The most important results were that white females were more extreme than white males, and that black males were more extreme than white males. It was further found that black females were more extreme in their responses than white females, and those with high anxiety were more extreme in their responses than those with low anxiety. Mahudar (2010) conducted a study aimed at identifying the nature of the relationship between extremism of response and the peripheral personality of university students, and the significance of differences according to gender variable. The researcher constructed two scales and used the descriptive correlative approach, where the researcher applied the two scales on a sample from the Faculty of Education in Al-Mustansiriya University. 
The most important reported results were as follows: low level of peripheral personality among university students, and the peripheral personality in males was less than in females which reacheda statistically significant level. Finally, it was found that there was no statistically significant relationship between the extremism of response and the peripheral personality.

\section{B) Studies dealing with psychopathy:}

Sarin et al. (1994) carried out a study aimed at investigating the relationship between sexual delinquency and psychopathy. The researcher used the descriptive and correlative approach and selected a sample of 62 sex offenders and 65 rape criminals who harassed children. The most significant results were as follow: There was a statistically significant correlation between psychopathy and sexual offenses. Moreover, the group of rape criminals on the psychopathic scale was higher than those of Child harassment criminals on the same scale. Belaid (2007) conducted a study aimed at identifying the characteristics and components of psychopathic personality in the Libyan society, and to reveal the relationship between psychopathic persons and drug addiction. The study also aimed at detecting psychological changes that occur to the addicted people when they discontinued using the drug, as well as detecting some psychological and social factors that are behind the addiction of psychopathic personality. The sample of the study consisted of (31) individuals selected by stratified random method, and the researcher used the descriptive correlative approach. The researcher designedand used a questionnaire which consisted of (55) items. The most important results were that drug use and addiction occur as a result of psychopathic personality disorders and that $32.3 \%$ of them are addicted to drugs as a result of emptiness and boredom.

\section{C) Studies dealing with intellectual deviation:}

Al-Khelaiwi (2017) conducted a study aimed at identifying the relationship between rumours in social media and intellectual security among secondary school students. The researcher used the rumour scale in social media and a measure of intellectual security. The sample of the study consisted of 694 students in a secondary school in Al-Riyadh. The researcher used the cluster method in this study. The most important results of the study were that the level of intellectual security of the students was high in all dimensions. The level of rumours in social media was low. There was also a statistically significant negative correlation between rumours in social media and intellectual security of secondary school students. In a study conducted by Al-Shammari, Jaradat (2011) aimed to know the role of faculty members in enhancing the intellectual security of students of the University of Hail where the researchers used the descriptive method. The sample of the study consisted of 173 faculty members from the University of Hail where the researchers designed and used a questionnaire to collect the data of the study. The main findings were as follow: There was an active role for faculty members in enhancing the intellectual security of students of the University of Hail in the areas of educational objectives, content of teaching, methods of teaching and evaluation. There were statistically significant differences attributed to experience on the role of faculty members in promoting intellectual security for the benefit of the faculty member with the greatest experience. Finally, there were many obstacles that face the faculty member to enhance the intellectual security of students, such as lack of clear plans and strategies for non-classroom activities.

Al-Ashqar (2010) conducted a study that aimed at identifying the role of non-classroom student activities in enhancing intellectual security. The researcher used two questionnaires: one measuring non-classroom activities and the other measuring intellectual security. The sample of the study comprised 384 secondary students. The researcher used the descriptive analytical method and the study revealed the following findings:

- Lack of programs that enhance intellectual security.

-Administrators and teachers work to consolidate the methodology of moderation and incorruptibility.

- Non-classroom student activities promote a culture of tolerance among students.

- The most important constraints were the lack of incentives, the high burden on the teacher and the poor financial allocations for the practice of non-classroom activities.

\section{Second: Studies dealing with two variables of the study:}

Al-Otaibi (2016) conducted a study aimed at identifying the relationship between extremism of response and psychopathy among secondary school students. The researcher used two measures of extremism of response and a measure of psychopathy, and she used the descriptive and correlative methodology. The sample of the study consisted of (451) secondary school students. The most important results of the study were that the level of extremism of the response of students was low regarding its various dimensions, i.e. persistence, psychological tension, intolerance to ambiguity, authoritarianism, prejudice, loss of self-confidence and introvert. Psychopathy was also low and there was a statistically significant positive correlation between psychopathy and extremism of response. Finally, psychopathy can be predicted by extremism of response and its various dimensions. 


\section{Study Assumptions:}

The study focuses on testing the validity of the hypothesis that the direct influence of extremism of response on intellectual deviation differs from that of indirect influence. In this study, a proposed model is presented in which extremism of response and individual psychopathy directly affect intellectual deviation. Extremism of response also influences intellectual deviation indirectly by psychopathy as a mediating variable. The proposed model isillustrated in Figure 1.

Figure (1) proposed model

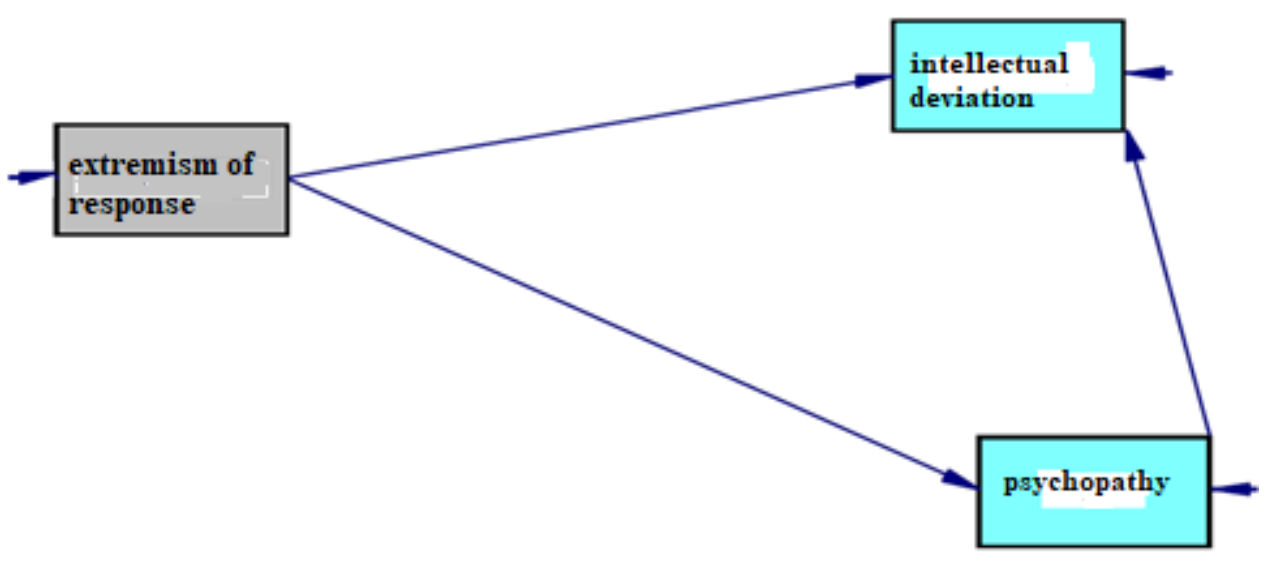

The second hypothesis in this study is the same as the previous proposed model but it differs in terms of the elimination of weak phrases in the three variables (extremes of response, psychopathy, and intellectual deviation).

\section{Methods}

Methodology of the study: Since the aim of the study was to build a systematic causal model of the relationship between extremes of response, psychopathy, and intellectual deviation, the researcher used the descriptive and correlative approach.

Study population:The study population consisted of all secondary school students (boys) in Riyadh, where the total number of students (46987) according to the statistical report issued by the Ministry of Education for the year (2018).

Study sample: The researcher used the cluster random sample, and hence (519) students were selected as the sample of this study.

Study tools: A variety of study tools were used to collect the data needed to answer the study research questions from the members of the community or members of the sample. Obeidat et al. (1998) pointed that the tools include a range of observation, interviews, questionnaires, tests and scales. The researcher in the current study used three scales as illustrated in Table (1)

Table (1) Tools of the study

\begin{tabular}{|l|l|}
\hline Scale & Prepared by \\
\hline Psychopathy from - MMPI & Louis Malika, 1974 \\
\hline Extremism in response & Ahmad Eid Mahudar (2012) \\
\hline Intellectual deviation & Awatef Al-Otaibi (2016). \\
\hline
\end{tabular}

With regard to the scale of extremism of response, it was designed by Mahudar (2012) and consisted in the final form of (60) paragraphs. As for the correction of the scale, it consists of five alternatives ranging from apply to a very large to not applicable to me at all. The first option is given five points, the second is given four points, the third (3), the fourth (2), and the fifth option is given (1) point. This is for positive paragraphs, while the negative paragraphs take reverse points. Therefore, the lowest degree on the scale is (60) and the highest degree is (300). As for the psychometric properties of the scale of the extremism of response, several reliability and validity coefficients have been reported in a number of studies. In the study of Al-Otaibi (2016), the discriminatory validity of the scale and internal consistency was verified. The correlation coefficients ranged from $(0,31)$ to $(0,82)$, all of which were statistically significant. In the present study, the internal reliability of the scale was verified, and the correlation coefficients ranged from 0,266 to 0,679 . The stability of the scale was verified in two ways. In the present study, the internal reliability of the scale was verified, and the correlation coefficients ranged from 0.266 to 0.679 . The reliability of the scale was verified in two ways. 
The Cronbach alpha reliability coefficient was 0.835 and the split-half correction with the Gutman equation was 0.070 . The Psychopathic Scale is a measure of the Minnesota Multifaceted Personality Scale (MMPI) which was translated by Malika (1974). There were three options for answering the scale in its American version: True-False-I don't know, while there were only two answers (yes-no) in the Arabic version. The psychopathic deviation scale consists of (50) paragraphs which measures the degree of similarity of the subject to the category of psychopaths who are characterized by a lack of deep emotional response, inability to benefit from experience and indifference to social standards. Therefore, the paragraphs of the scale ranged between zero to 50 degrees. As for the correction key, please see Table 2.

Table (2) Correction key of psychopathy scale

\begin{tabular}{|l|l|}
\hline Yes & $\begin{array}{l}\text { Items No. : -239-224-216-215-127-118-110-106-102-94-84-67-61-42-38-35-33-32-24-21-16 } \\
284-245-244\end{array}$ \\
\hline No & $\begin{array}{l}\text { Items No. : -248-237-235-231-201-183-180-173-170-155-141-137-134-107-96-91-82-37-20-12 } \\
296-294-289-287-267\end{array}$ \\
\hline
\end{tabular}

As for the psychometric properties of the psychiatric scale,Al-Otaibi(2016) checked the psychometric properties of the scale and found the internal consistency where the correlation coefficients ranged from $(0,297)$ to $(0,507)$, all of which are statistically significant. For the present study, the researcher calculated the internal consistency of the scale and the correlation coefficients ranged between 0.321 to 0.608 . These values are deemed acceptable since the scale had only two response. With regard to the scale of intellectual deviation (Otaibi, 2016), the scale included 24 positive statements. The responses of the scale were corrected based on five responses as explained in Table 3.

Table (3) correction key of Intellectual deviation scale

\begin{tabular}{|l|l|l|l|l|l|}
\hline $\begin{array}{l}\text { The connected } \\
\text { response }\end{array}$ & Strongly agree & Agree & $\begin{array}{l}\text { Moderately } \\
\text { agree }\end{array}$ & Disagree & Strongly disagree \\
\hline Score & 5 & 4 & 3 & 2 & 1 \\
\hline
\end{tabular}

The validity of the scale was verified using two methods: the validity of the referees and the internal consistency. The initial version of the scale was presented to a number of psychologists and those involved in intellectual security. By analysing the opinions of the referees, it was decided to keep all the paragraphs. The rate of agreement was above $(80 \%)$, and the researcher did not rule out any paragraph because all of them were more than (80\%). The Pearson correlation coefficient was calculated between the degree of each paragraph and the total score of the scale. All correlations were statistically significant and ranged from 0.307 to 0.619 . Reliability was calculated in two ways, where the validity value of the Cronbach Alpha method was 0.808 . The reliability value of the split-half method after correction using the Gutman equation was 0.750 which is considered acceptable. For the present study, the researcher calculated the internal consistency of the scale and the correlation coefficients ranged from 0.450 to 0.719 , and the value of reliability using split-half method after correction using Gutman equation was 0.780 .

\section{Study Results}

Since the focus of this research is to test the proposed model which includes the three variables, i.e.extremism of response, psychopathy, and intellectual deviation, the correlative matrix of the three variables was calculated, and then the matrix containing these partial correlations was used in the model test using LISERAL application. Table (4) shows the indicators of 'goodness of fit' between the research data and the two proposed models.

Table (4) Indicators of good match

\begin{tabular}{|l|l|l|l|l|l|l|l|l|l|}
\hline Sample & NNFI & NFI & SRMR & RMSEA & AGFI & GFI & P & $\mathrm{x}^{2}$ & N \\
\hline First model & 0,96 & 0,96 & 0,080 & 0,055 & 0,97 & 0,96 & 0,211 & 1322 & 514 \\
\hline Second model in case of deleting weak items & 0,97 & 0,98 & 0,071 & 0,054 & 0,98 & 0,98 & 0,279 & 1439 & 514 \\
\hline
\end{tabular}

It is clear from Table (4) that the two proposed models apply to the sample of the study because of the small value of $\mathrm{ka}^{2}$ and the insignificance value of $p$. The values of GFI, AGFI NFI, NNFI are greater than 0.90 and approaching one. The value of RMSEA was less than 0.70, and SRMR value was also less than.090 (Hu \& Bentler, 1998; MacCallum \& Austin, 2000; Marsh et al., 1998; Malika et al., 1989).

\section{The first hypothesis:}

The study focuses on testing the validity of the hypothesis that the direct influence of extremism of response on intellectual deviation differs from that of indirect influence. First: the direct effects of extremism of response and psychopathy on the intellectual deviation of the study sample of the study as illustrated in Figure (2): 
Figure (2) the direct effects of extremism of response and psychopathy on the intellectual deviation.

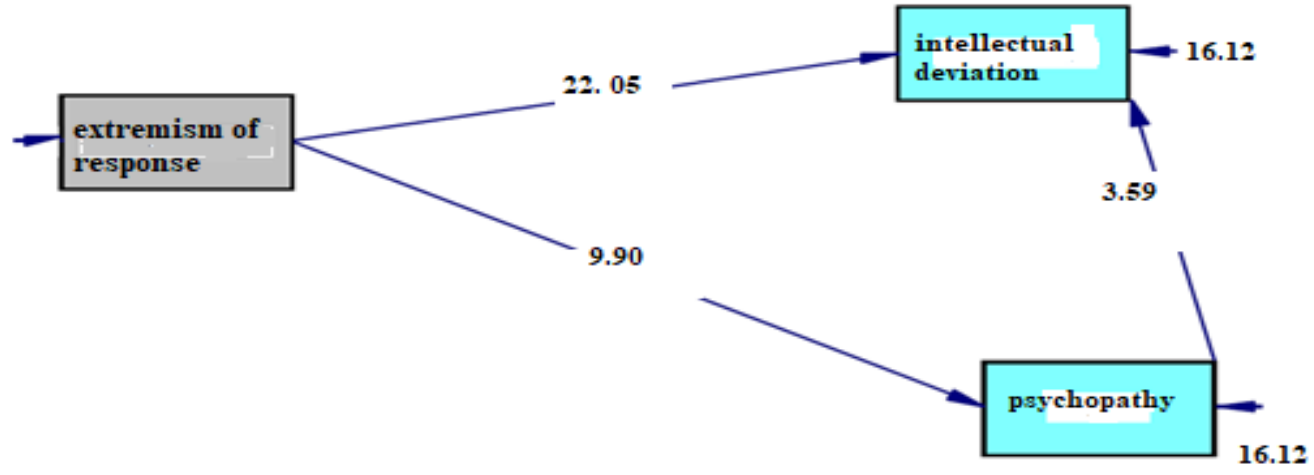

The path of extremism of response to intellectual deviation $=0,697$, which is statistically significant, while the $t$ value of " is 22.05 , which is greater than the value of 1.96. This means that the extremism of response in the study sample has an effect on the intellectual deviation, and that the path of extremism of response to psychopathy is 0.398 , which is statistically significant at the level of 0.05 , while the $t$ value is 9.90 which means that the extremism of response has an effect on psychopathy. As for the path of psychopathy to intellectual deviation, it is 0.114 which is statistically significant at the level of 0.05 , while the $t$ value is 3.59 which means that psychopathy has an effect on intellectual deviation of the sample of this study.

Second: The indirect effects of extremism of response and psychopathy on intellectual deviation:

The influence of extremism of response to intellectual deviation through psychopathy as an intermediate variable (a dependent variable for extremism of response variable and an independent variable for the intellectual deviation variable). Therefore, the path will be "extremism of responseto psychopathy to intellectual deviation". This effect consists of multiplying the regression coefficients in these two paths. Thus, the indirect effect of extremism of response in the case of the mediation of psychopathy on the intellectual deviation of the study sample as follows: The effect of the path $=0.398 \times 0.045=0.114$. This means that there is no indirect effect of extremism of response on intellectual deviation through psychopathy. And this effect is relatively small to make a direct effect between extremism of response and intellectual deviation without the mediating of psychopathy. The direct effect was 0.697 which is equivalent to about fifteen times the value of the indirect effect of extremism of responseon intellectual deviation in the presence of an intermediate variable, i.e. psychopathy.

\section{The Second hypothesis:}

The second hypothesis in this study is to impose the same model as the previously proposed but after deleting the weak statements in the study variables (extremism of response, psychopathy). To answer this hypothesis, all weak statements were deleted from the extremism of response, psychopathy variables. It was decided to delete (16) paragraphs from extremism of response and (5) paragraphs from the psychopathy variable, as these paragraphs were very low. However, no paragraph was omitted from the intellectual deviation variable as all paragraphs were strong. First: the direct effects of extremism of response and psychopathy on the intellectual deviation of the study sample, as shown in Figure (3):

Figure (3) the direct effects of extremism of response and psychopathy on the intellectual

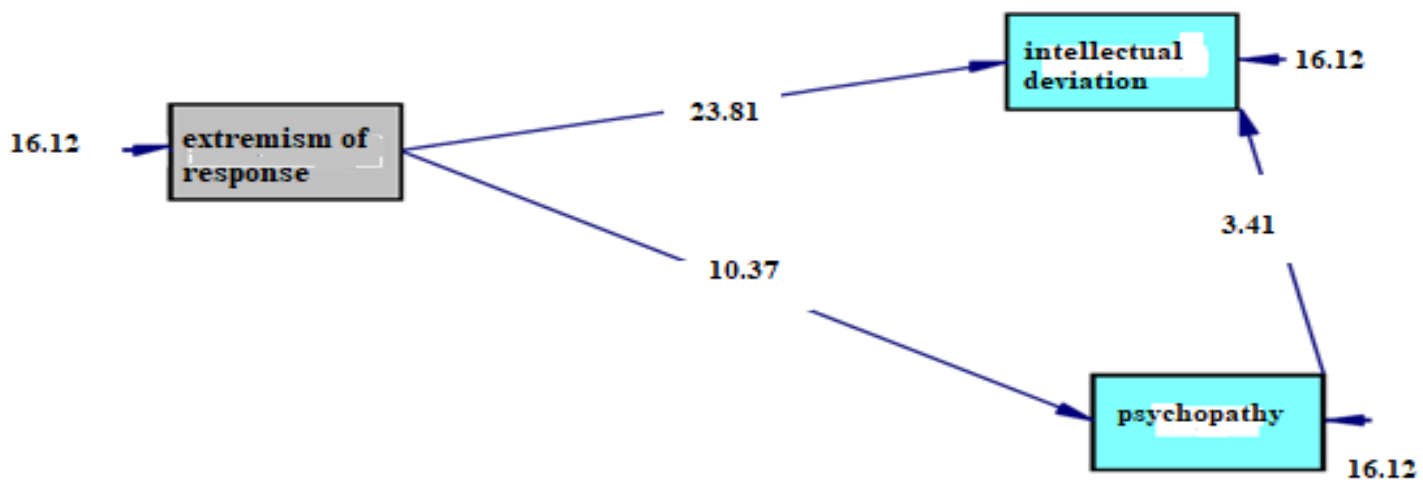

The path of extremism of response to intellectual deviation $=0.726$ which is statistically significant, while the $t$ value is 23.81, which is greater than the value of 1.96 . 
This indicates that extremism of response of the study sample has an effect on intellectual deviation. Moreover, the path of extremism of response to psychopathy equals 0.414 which is statistically significant at the level of 0.05 . The $t$ value is 10.37 , which means that psychopathy affects the intellectual deviation of the study sample.

Second: The indirect effects of extremism of response and psychopathy on intellectual deviation: For the effect of extremism of response onintellectual deviation through psychopathy as an intermediate variable (a dependent variable for extremism of response and an independent variable for psychopathy). Thus, the path is as follows: "extremism of response to psychopathy to intellectual deviation." Therefore, the indirect effect of extremism of response in the case of psychopathy as a mediator on the intellectual deviation of the study sample is as follows: The effect of the path $=0.414$ $\mathrm{x} 0.043=0.104$. This means that there is an indirect effect of extremism of response on intellectual deviation through psychopathy. And this effect is relatively small to make a direct effect between extremism of response and intellectual deviation without the mediating of psychopathy. The direct effect was 0.726 which is equivalent to about seventeen times the value of the indirect effect of extremism of response on intellectual deviation in the presence of an intermediate variable, i.e. psychopathy.

\section{Discussion of the results:}

Based on the results of this study, it is clear that the findings supported the validity of the two main hypotheses of the research, namely that the direct influence of extremism of response on intellectual deviation is clearly different from the indirect effect. Though both types of impact were statistically significant, the direct impact of extremism of response on intellectual deviation was multiplied many times than the indirect effect. This means that the concept of psychopathy does not play the role of a mediator variable in the relationship between extremism of response and intellectual deviation. As for the direct impact of extremism of response on intellectual deviation, this can be explained and discussed according to the nature of the sample of the study, i.e. secondary school students who were exposed to three measures. A student who tends to radicalize his response significantly has more tendency towards intellectual deviation. The correlation between extremism of response and intellectual deviation was 0.74 which was statistically significant at the level of 0.05 or less. The research results supported the absence of a meditating model in which psychopathy does not play an intermediate role between a sensitive and dangerous variable for secondary school students, i.e. extremism in response and intellectual deviation. This can be explained by the fact that high school students in Riyadh do not have a psychopathical status. Students are bound by agreed laws and standards inside and outside the school. Students cannot break laws or even ethical standards within the community. Every student who surpasses these standards must be held accountable both inside and outside the school. Moreover, Saudi society is a conservative society that adheres to the Arab customs and traditions. Therefore, any behaviour that is unlawful by any member of society including high school student will be met with severe criticism and disapproval because it is considered extraordinary and contrary to the laws and ethical standards which are agreed upon by members of society. Consequently, it shall be held accountable by law for any action that violates the moral standards of society. Building relationships which this study suggests can guide the educational and psychological stakeholders to make an effort to reduce intellectual deviation and ideas that lead to this path.

Instead, stakeholders should focus on enriching the concept of extremism of response to help students build their personality throughout all stages of the school, especially in the secondary stage, so that his personality is strong and stable. This will help those students feel safety, security and stability and thus they stay away from the problems that cab be a source of intellectual deviation (e.g., insecurity and tranquillity).Understanding the beliefs that enhance the ability to counter the thoughts and pressures which can cause intellectual deviation is vital for psychiatric practitioners. Such knowledge can help them address the person suffering from intellectual deviation. If a person's beliefs and perceptions(e.g., the power of personality) can be acted as a mitigator of extremist ideas, then the psychologist can spend more time helping the individual establish the concept of personality building. The findings of this research show that the variable that should be the focus of intervention of students with intellectual deviation, which turns to be a key factor in promoting intellectual deviation is exposure to negative life events such as: family problems, vacuum, poverty, etc. In addition to other events that affect the building of an individual's personality, which makes them more inclined to become radical in their response. Therefore, the focus should be placed on those students to minimize disturbing events in their lives that affect their characters and level of security. Targeting secondary school students for their intellectual deviation is not only a personal problem, but a social issue that affects the whole society. The solution is partly to change the educational practices that are behind these false beliefs. It makes the student's personality strong and builds their sense of a stability and high security level so that the student's tendency to extremism of response and intellectual deviation become very difficult. 
At the end of the commentary on the results of this research, the results showed that extremism of response affects the students' intellectual deviation. Reduce it is possible by focusing on building a strong, open and discreet personality of high school students.

Recommendations:- Put vocabulary or terminology in some the syllabi of some subjects such as Arabic language that focus on building the character according to scientific foundations that are applicable.

Proposals:- Build a causal model for the following variables: extremism of response, intellectual deviation and depressive symptoms.

\section{References}

Al-Ashqar, M. (2010) the role of non-classroom student activities in promoting intellectual security, unpublished Ph.D. thesis, Naif security university, Riyadh, college of graduate studies, department of social sciences.

Al-Juhani, F. (2004). Family function in strengthening intellectual security. The Journal of Policing Thought. 12 (48), 122-143.

Al-Khalidi, A.(2007). the effect of two extension methods in modifying the marginal personality of the preparatory stage students, unpublished Ph.D. dissertation, Mustansiriya University, Iraq. faculty of education.

Al-Khelaiwi, R. (2017). Rumors in social media and its relation to intellectual security among university students, unpublished master thesis, Naif Security University, Saudi Arabia, Faculty of Social Sciences, Department of Psychology.

Al-Otaibi, A. (2016). Extremism in response and its relationship with psychopathology, Unpublished Ph.D. Dissertation, Naif Arab University for Security Sciences, Riyadh, College of Social Sciences, Department of Psychology.

Al-Shammari, M and Jaradat, M. (2011). The role of faculty members in promoting intellectual security among students of Hail University. Arab Journal of Security Studies. 27 (54) 153-200.

Arseneault, L; Terembaly, R; Boulerice, B ;Segum, J \& Saucier , J(2000).Minor physical anomalies and family adversity as risk factors for violent delin-quency in adolescence, Am J Psychiatry, 157 (6) , 917-923.

Assi, A. (2006). Violence in the world. Palestine: Ministry of Women Affairs: Studies and Policies Department.

Barakat, M. K.(1995). psychiatric and mental health clinics, Kuwait: Dar Al-Qalam.

Belaid, N. (2007). psychopathic personality and its relationship to drug addiction popular Tripoli. unpublished master thesis, Omdurman Islamic University. Sudan, faculty of arts, department of psychology.

Berg, I.A., \& Collir, J.S.(1953). Personality and group differences in extreme response sets, Educational and Psychological measurements.

Brengelmann, J.C.A. (1960). Note on questionnaire rigidity and extreme re-sponse set . Journal of Mental Science.

Hu, L., \& Bentler, P.M. (1998). Fit indices in covariance structure analysis: Sensitivity under parameterized model misspecification. Psychological Methods, 3(2),424 - 453.

Ibn Manzaru, A .(1999). Lisan al-Arab, Volume (9), Lebanon : Dar Sader.

Joreskog , K. G. (1970). A general approach to confirmatory maximum likelihood, factor analysis. Psychometrika, 34(5),183- 202.

MacCallum, R.C., \& Austin, J.T. (2000). Application of structural equation modeling in psychological research. AnnualReviewof Psychology, 51(9), 201-226.

Mahudar, A. (2010). Extremis in responsa and its Relationship with the Marginal Personality of UniversityStudents, Unpublished Master Thesis, Iraq : Mustansiriya University, College of Education.

Majdoub, A. (2003). the devil in our home, Cairo: The Anglo-Egyptian Library.

Malika , L. (1974). MMPI Cairo: test guide.

Mansour, G. (2014). Psychopathological attitudes towards society and its relation to some study variables among a sample of students of Damascus University. Journal of the Federation of Arab Universities for Education and Psychology, 12 (3) 110-133.

Marsh, H.W., Hau, K.T., Balla, J.R., \& Grayson, D. (1998). Is more ever too much? : The number of indicators per factoring confirmatory Factor analysis. Multivariate Behavioral Research, 33(11), $181-220$.

Moon, B. K. (2007). Violence againstwomen - facts and numbers, report of the UN Secretary-General.

Mulaik, S.A ., Jams ,L.R ., Alstine , J.V ., Bonnett, N., lind, S., \& Stilwell, D. C. (1989). Evaluation of goodness of fit indices for structural equation models. Psychological Bulletin, 105(16), 430 - 445.

Nowaak, M. (2008). Promote and protect all civil, political, cultural, economic and social humanrights, including the right to development. Report of the Special Rapporteur on torture and other cruel, inhuman or degradingtreatment or punishment, HumanRights Council Seventh session, agenda item III.

Obeidat, D. (1998). Scientific Research: concept, tools and methods, Amman: Dar Al-Fikr.

Rifai, H. (1991). Prevention of juvenile delinquency, Sharjah: Journal of Policing Thought 3 (4), 77-102. 
Saad, A and Na'amah, S. (1993). Personality and Production, Damascus: Damascus University.

Sarin, A., Clerici, M., Blat,. S.P., Hendrix, C.W., Shearer, G.M.,\&Henkart, P.A.(1994).Inhibition of activation induced programmed cell death and restoration of defective immune responses of HIF+ donors by cysteine protease inhibitors. J. Inmnmol., 153(2), 862-872.

Shahrani, S. (2005). Intellectual Deviation and its Impact on the National and Collective Security of the Cooperation Council for the Arab States of the Gulf, Riyadh: Naif Arab University for Security Sciences.

Sharabajee, A.(1981). Multiple linear regression. Ministry of Education and Scientific Research, University of Mosul: Iraq.

Zuhaili, M.(1993). Islam and Youth 2ed. Damascus: Dar Al-Qalam. 